\title{
Actualizing Moodle Interactive Tools Usage within Distance Learning: Need for Multilevel Approach
}

\author{
Jekaterina Bierne
}

\begin{abstract}
This article presents the results of two focus groups study including distance learners and teachers from Latvian colleges using Moodle for distance learning. Study is problem-focused in order to reveal teachers and students experienced barriers with using Moodle interactive tools and provides brief insights into possible causes of restrained activity of both sights. It also suggests multilevel approach for actualizing Moodle interactive tools usage within distance learning in order to create more dynamic and interactive virtual learning environment.
\end{abstract}

Index Terms-Interactive learning environment, distance learning, higher education, moodle.

\section{INTRODUCTION}

Modular Object Oriented Dynamic Learning Environment known as Moodle is used in Latvia both in higher education and secondary schools [1] The process of integrating Moodle technology in Latvian education system takes part simultaneously on different levels. This means that in nearest future colleges will have generation of students, who are fully prepared to use Moodle in their learning activities. The development of distance learning in emphasized in the basic EU documents relating to education and in Latvia as well [2] Change in the society leads to changes in educational system, and majority of higher education institutions in Latvia have accepted this challenge. On the other hand, for now Latvian distance learners, as well as teachers in higher education institutions usually have no previous experience in using Moodle. It should be also taken into account that many distance learners decide to continue their learning after long years outside educational system, therefore they have no experience with virtual learning environment.

In Latvia Moodle implementation gets more examined at secondary school level, than at higher education level. In case of distance learning, when students are located in different places, sometimes outside the state, are not attending lectures and seminars and are learning in preferred time, place and step, Moodle platform is the main tool in Latvia, which allows providing such type of learning [3] Historically, distance learning process and instruments were minimally interactive (typographically printed guidelines and textbooks, sent written assignments and exams, rare consultations with teachers in previously arranged time and place, no collaboration with other students) [4] Moodle platform includes wide range of virtual tools, which helps to make

Manuscript submitted November 15, 2012; revised December 12, 2012. Jekaterina Bierne is with University of Latvia/Faculty of Education, Psychology and Art, Riga, Latvia (email: jekaterina.bierne@eka.edu.lv). process of distance learning interactive, communicative and collaborative, creating virtual learning community of distance learners. Nevertheless, actualization of its interactive potential within distance learning is not an easy task for higher education institution with no previous experience in using virtual learning environment.

Knowledge based society focuses on enabling person to have greater use on technological informational opportunities. Moodle is such an opportunity itself and enables teachers and students to collaborate and create interactive learning environment which produces knowledge effectively. Initializing of Moodle platform usage in Latvian higher education institution typically takes place order to offer additional educational options and to preserve competitiveness at higher education market [5] Thus teachers encounter requirement to modify their traditional course and to transform it into e-course. There are different models of using Moodle platform within Latvian higher education institutions: as supportive instrument within blended learning or as main instrument in distance learning. University College of Economics and Culture, which is author's workplace, just started realize distance learning programs with Moodle in 2012, whilst University of Latvia or Riga Technical University uses it for years mostly (but not exceptionally) within blended learning model. But typical problem remains the same: non-interactive resources are dominating more than desirable, which is especially perceptible at institutions less experienced in the sphere of web-based virtual learning. In the case of blended learning problem seems no to be crucial (students are attending traditional lectures and seminars, but Moodle resources are mostly playing supportive and structuring role), in the case of distance learning this seems to be much more considerable problem. Need for interaction is one of the basic pedagogical principles, and it seems obvious, that domination of non-interactive resources not helping to achieve good learning outcomes. Just existence of virtual learning tools and accessibility of teachers' prepared materials don't create dynamic environment for active learning. For now University College of Economics and Culture encounters new challenge: how to actualize Moodle interactive potential and usage of platform's interactive tools in order to create really interactive and collaborative learning environment, which produces knowledge and stimulates its exchange.

\section{METHOD AND RESUlts}

\section{A. Method}

In order get insight in the reasons of restrained use of 
interactive tools in Moodle within distance learning, interviews in two focus groups were conducted. First focus group included 7 distance learners from 2 Latvian colleges and universities (University College of Economics and Culture and University of Latvia). 4 of participants are first year students, 3 are second year students. Another focus group included 7 teachers working within distance learning programs in the same higher education institutions, which agreed to share their experience with Moodle. Two 2 hours discussions were conducted in 2012 November. Discussions were focused on interactive and non-interactive resource usage experience, students and teachers ideas about possible causes of not especially active usage of interactive tools within virtual learning environment. Discussions within two groups were intentionally problem-focused in order to reveal experienced barriers. Main questions for students and teachers were focused on two interconnected issues: 1) those factors, which could possibly be embarrassing or troubling regarding interactive tools usage within Moodle 2) possible solutions or helping factors, which could enable and stimulate interactive tools usage in order to create more interactive learning environments.

\section{B. Students Perspective}

From students' perspective, one of the factors, which is playing troubling role is that teachers not always offering interactive tasks and creating interesting and attractive environment within the e-course ("for instance, he rarely appears and replies, and offer nothing interesting except to read course materials and added files such as articles and presentations"), making Moodle rather "files box" than really interactive virtual learning environment. If teacher is enthusiastic enough and offering collaborative tasks and is stimulating interactivity and communication, next troubling factor reveals: lack of time for taking part in it. Partly it's a problem of e-learning process management, which is especially actual in the case of distance learning, and to some extent this is motivational issue ("maybe I'm not such enthusiastic about learning by myself", "as distance student I'm very busy with my work and family commitments, it's enough for me to match minimal obligatory requirements and I have no time to something additional"). During the discussion another issue revealed: asynchronous communication and need for autonomous pace of learning. If in traditional educational framework lections, seminars and workshops are dictating common unified regime of teaching, learning, interaction and collaboration, distance learners are tended to organize learning and to participate in their own pace and style ("Sometimes I'm not learning at all for a whole month or two, because I have great amount of work to be done in the company, then I'm "back to school" trying to compensate this period of time"). Focus group participants recognized, that they are often practicing passive observation of Moodle activities and following teachers and another students contribution (like reading forums and blogs) with no active contribution by themselves, which is another one embarrassing factor ("I just try to get what's going on there, sometimes I have nothing to say, to initialize or to add"). This makes to presume that students may seem their own role as the passive consumers, no enriching learning environment by themselves. It is needed to emphasize, that discussion was intentionally problem-focused. As helping factors high learning motivation, communicative supportive teacher, interesting tasks and clear guidelines for participation were mentioned.

\section{Teachers Perspective}

From teachers' perspective, there are some difficulties with engaging students in communication and collaboration within e-course ("Initialized discussions about course topics stop after couple of posts", "They have nothing to say and to show because they are not studying properly"), which is one of factors, which make creation of interactive virtual learning environment not an easy task. Next issue revealed during discussion sounds precisely as in students' case: the lack of time due to regular workload. One of the troubling factors is the lack of clear idea about what it means to manage e-course in distance learning effectively and sufficiently, which activities and to what extent are expected from teacher and when these activities should take time ("It sounds like question of teacher's personal enthusiasm after working day"). To some extent this could be formulated as deficit of clear reasons to develop actively virtual learning course (after its creation) and to invent innovative pedagogical solutions within it.

Another part of discussion revealed teachers experience regarding lack of e-course management guidelines ("It's easy for administration to say that someone is not doing it properly and not active enough as e-teacher, but we all have workload with full time students, plus there are no clear idea what it means to be "active enough").

As helping factors readiness to develop professional competence, devotion to profession, guidelines for didactical solutions and clear administrative framework were mentioned.

Both groups reported, that only in a case, when engagement in interactivities and collaboration is strictly structured and defined as a course requirement, it takes part, but discussion within teachers group actualized another aspect: lack of methodological ground and need for developed e-learning didactics ("Sometimes teacher is not really sure, how to restructure traditional course into such mode, especially taking into account asynchronous communication in virtual environment").

TABLE I: MultileVEl PERSPECTIVE OF MOODLE INTERACTIVITIES ACTUALIZATION PROBLEMS

\begin{tabular}{|c|c|c|}
\hline $\begin{array}{l}\text { Students } \\
\text { perspective }\end{array}$ & Teachers perspective & Institutional perspective \\
\hline $\begin{array}{l}\text { 1.Teachers are not } \\
\text { engaging enough } \\
\text { in interactivities } \\
\text { 2.Lack of time to } \\
\text { be an active } \\
\text { contributor } \\
\text { 3.Lack of clear } \\
\text { reasons and } \\
\text { motivation } \\
\text { 4.Lack of } \\
\text { pedagogical } \\
\text { guidelines }\end{array}$ & $\begin{array}{l}\text { 1.Students are not } \\
\text { engaging enough } \\
\text { 2.Lack of time to } \\
\text { develop innovative } \\
\text { and interactive } \\
\text { teaching techniques } \\
\text { 3.Lack of clear } \\
\text { reasons } \\
\text { 4.Lack of e-didactical } \\
\text { and administrative } \\
\text { guidelines }\end{array}$ & $\begin{array}{l}\text { 1.Need for methodological } \\
\text { background, pedagogical } \\
\text { and administrative } \\
\text { guidelines for e-courses } \\
\text { management } \\
2 \text {. Need for criteria of } \\
\text { successful performance of } \\
\text { e-course management }\end{array}$ \\
\hline
\end{tabular}

Table I shows synthesis of focus groups experience and 
similarity of main ideas of students and teachers about factors which causes restrained usage of Moodle interactive tools. It includes idea of institutional perspective as well, as possible response to mentioned problem, partly reflecting possible solutions or helping factors, which could enable and stimulate interactive tools usage in order to create more interactive learning environments.

This insight in teachers and students ideas about possible causes of restrained usage of interactive tools within virtual learning environment leads to conclusion that the process of transformation of learning and teaching methods within Moodle environment should be carefully studied in Latvian higher education institutions.

\section{DiscussiION}

Making virtual learning environment really interactive and attractive is serious practical challenge encountered by higher education institutions starting to use Moodle. It is important from the viewpoint of finding ways and means to improve quality of distance learning.

The study shows that clear framework needed for adoption such technological change. Students are not engaging in virtual educational interactivities, if there are no clearly defined reasons for them to do this. Teachers are not developing interactive virtual resources within their course and supporting communication and collaboration within virtual learning environment, if there are no clearly defined reasons to do this as well. Students need to have methodological background and definite guidelines from teacher to engage in using Moodle interactive tools and to participate in virtual learning activities. Teachers need not only creative thinking and new attitude to transform teaching techniques [6] but methodological background in e-didactics and guidelines for creating interactive virtual learning environment. Higher education institution administration should create comprehensive framework for optimal usage of virtual learning environment, communicate the criteria of sufficient e-course management and successful performance. Reducing this issue to just measuring learning outcomes potentially would not help to provide needed guidelines for qualitative e-course management, including pedagogical usage of interactive virtual tools. It is possible, but not exceptional way, because it focuses on measuring results rather than process of creating interactive and collaborative environment for qualitative learning process. Modernization of higher education by integrating the ICT such as Moodle platform highlights challenges related to shift in learning paradigm [7]. Tools and options, as well as information about how to use them, do not cause optimal educational usage of them. Researches about virtual learning environment implementation problems in education system in Latvia were mostly focused on digital literacy issue [8] This was relatively actual problem within definite period of time, but for now it's acknowledged, that both teachers and students nave no problems with digital literacy, they are actively using social networks, portals, e-libraries and other online resources, which implicates accessing and sharing information. In the case of Moodle, educational technology highlights possibly deeper underlying problem. Distance learning and virtual learning philosophy bases to large extent on learning as a ultimate value and self-motivation as undoubtedly needed factor for active taking part in learning process and achieving good learning outcomes [9] Without this, virtual learning environment is not producing knowledge regardless digital literacy or any other factors [10] When students and teachers interaction realizes by the means of technological tools and can be shown as a log of definite activities usage, making it traceable and measurable, it reveals gap between desirable situation and real educational practice. Self-motivation definitely should be supported by some pedagogical and administrative tools, in order to prevent tendency to minimize contribution (both from students and teachers) in creating interactive learning environments, producing knowledge and achieving learning outcomes. In order to avoid unproductive situation, which is possible in case of lack of experience in using virtual learning environment as Moodle, when college administration has no clear idea about how to stimulate teachers to be the good course managers, teachers have no clear idea how to do this and which are criteria for successful performance, and students have no clear idea about their active role, comprehensive and stimulating framework is needed to support distance learning in virtual learning environment at all involved levels.

During the focus group interviews main questions were focused on two interconnected issues: embarrassing or troubling factors regarding interactive tools usage within Moodle and possible solutions or helping factors, which could enable and stimulate interactive tools usage in order to create more interactive learning environments. Students mentioned development of practical professional interests and issues, that stimulates them to learn and to search for solutions, but teachers - readiness to develop professional competence and devotion to profession, but both groups emphasized need for pedagogical and administrative guidelines, which consequently leads to idea about multilevel approach needed for actualizing interactive tools usage and creation of attractive and interactive learning environment within distance learning.

Table II shows multilevel approach to actualizing Moodle interactive tools usage within distance learning in order to create interactive and dynamic virtual learning environment.

Progression towards knowledge-based society and the respect for European dimension of education lead to the implementation of new educational technologies in Latvian colleges and universities. In this process some gaps get identified between technological, pedagogical and administrative innovation within higher education practice. In order to overcome this gap and to stimulate productive implementation of advanced educational technology, multilevel approach is needed, providing both pedagogical and administrative guidelines at the level or students, teachers and distance learning administrators, which could help to structure and to promote needed innovations, collaboration and knowledge producing in virtual learning environment. This study provided brief insight into distance learners and teacher experience and their ideas about possible causes of restrained usage of interactive tools within virtual 
learning environment. This study helped to structure framework for author's planned research about educational innovations within Modular Object Oriented Dynamic Learning Environment in distance learning at Latvian higher education institutions. Reviewing obtained results will also help author to work out the multilevel framework for Moodle implementation improvement at University College of Economics and Culture.

TABLE II: MULTILEVEL APPROACH TO ACTUALIZATION OF MOODLE INTERACTIVE TOOLS USAGE WITHIN DISTANCE LEARNING

\begin{tabular}{|c|c|}
\hline Level of student & $\begin{array}{l}\text { 1.Clear reasons for participating in } \\
\text { interactivities and collaboration } \\
\text { (pedagogical background focusing on } \\
\text { learning outcomes achievement through } \\
\text { interaction) } \\
\text { 2.Requirements and criteria for sufficient } \\
\text { participation in e-course } \\
\text { 3.Clear communication about expected } \\
\text { learning outcomes }\end{array}$ \\
\hline Level of teacher & $\begin{array}{l}\text { 1.Clear reasons for actualizing Moodle } \\
\text { interactive and communicative tools and } \\
\text { integrating them into e-course (didactical } \\
\text { background focusing on creating } \\
\text { interactive learning environment with } \\
\text { virtual techniques) } \\
\text { 2.Criteria for sufficient e-course } \\
\text { management performance } \\
\text { 3.Clear communication of expectations } \\
\text { about collaboration model within } \\
\text { distance learning }\end{array}$ \\
\hline Level of HE institution & $\begin{array}{l}\text { 1.Grounded criteria of successful } \\
\text { realization of distance learning } \\
\text { 2.The model of successful usage of } \\
\text { Moodle platform within distance } \\
\text { learning } \\
\text { 3.Clear communication of expectations } \\
\text { and criteria of sufficient e-course } \\
\text { management performance }\end{array}$ \\
\hline
\end{tabular}

\section{CONCLUSIONS}

1) Process of transformation of learning and teaching methods within Moodle environment should be carefully studied at Latvian higher education institutions.

2) Teachers and students experience with educational technology like Moodle shows, that clear and stimulating framework is needed to structure distance learning in virtual learning environment.

3) Nevertheless Latvian researches about virtual learning environment implementation in higher educations are mostly focused on digital literacy issue, Moodle as educational technology highlight deeper underlying problems like tendency to achieve defined outcomes with minimal engagement and contribution both from students and teaches when there is no clear, supporting and stimulating framework, both didactically and administratively grounded.
4) Higher education institution administration should create comprehensive framework for optimal usage of virtual learning environment and communicate definite criteria of sufficient e-course management and successful performance.

5) Actualization of interactive tools usage and development of interactive virtual learning environment on the base of Moodle within distance learning in higher education institution needs the multilevel approach.

\section{REFERENCES}

[1] R. Birzina, "E-Learning for Lifelong Learning in Latvia," ASEM White Paper e-Learning for Life-Long Learning, Korea National Open University Press, 2012, vol. II, pp. 5-140, ISBN 978-89-20-00951-8 93370.

[2] Basic Guidelines of Lifelong Learning Policy for 2007-2013, Ministry of Education and Science LR, 2007.

[3] I. Gorbans. "Decisive ICT Options in the System of Development of School Education Policy in Latvia at tge Dividing Line of the Future Digital Decade," Ph.D. dissertation, Dr. sc. Administer, University of Latvia, Riga, 2008.

[4] I. Ivanova, "Handbook of distance learning," Rĭga: IU Mācību apgāds, 1999, pp. 106.

[5] B. F. Misnevs, "E-learning in Latvia. Dimensions of E-Learning Education In Latvia," Cases on challenges facing e-learningand national development: Institutional Studies and Practices, Turkey: Anadolu University, vol. I. pp. 379-409, ISBN 978-975-98590-8-4, 2010.

[6] I. Maslo and M. J. Fernandez-Gonzalez. "The central role of educational leadership for developing students' intrapreneurship attitudes in higher education settings: a case study from Latvia," Entrepreneurship education - a priority of higher education institutions, C. Martin and E. D. Budapest, Eds. October 8-12, 2012. ISBN 978-88-7587-656-2.

[7] R. B. Barr and J. Tagg. (15.10.2012). From Teaching to learning - A new paradigm, of Undergraduate Education. [Online]. Available: http://www.ius.edu/ilte/pdf/BarrTagg.pdf

[8] R. Birzina, "Humanistic approach within the study of adults' computer literacy," Ph.D.dissertation, Dr.Paed. University of Latvia, Riga, 2008.

[9] J. Hollowell, Moodle as a Curriculum and Information Management System, Packt Publishing, 2011, pp. 308, ISBN-13: 978-1849513227.

[10] B. Fetaji and M. Fetaji, "e-Learning Indicators: a Multi-Dimensional Model for Planning and Evaluating e-Learning Software Solutions," Electronic Journal of e-Learning, vol. 7, no. 2, 2009, pp. 1-28.

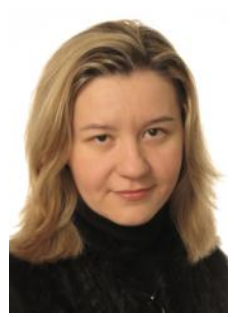

Jekaterina Bierne was born in Riga, Latvia in 1976. She graduated from University of Latvia (Riga, Latvia) in 2002 as Master of Psychology (Ma Psych). Currently she is a doctoral student of University of Latvia, Faculty of Education, Psychology and Art. She was working as a lecturer at University of Latvia in 2002 - 2005. From 2005 till current moment Ms. Bierne is the assistant professor at University College of Economics and Culture in Riga, Latvia. Current research interests relates to virtual learning environment in higher education, pedagogical innovations and e-learning didactics in higher education. 